\title{
Transcriptional regulation and spatial interactions of head-to-head genes
}

Yunqin Chen ${ }^{1,2}$, Yixue $\mathrm{Li}^{1,3}$, Jia Wei ${ }^{2^{*}}$ and Yuan-Yuan $\mathrm{Li}^{1^{*}}$

\begin{abstract}
Background: In eukaryotic genomes, about $10 \%$ of genes are arranged in a head-to-head $(\mathrm{H} 2 \mathrm{H})$ orientation, and the distance between the transcription start sites of each gene pair is closer than $1 \mathrm{~kb}$. Two genes in an $\mathrm{H} 2 \mathrm{H}$ pair are prone to co-express and co-function. There have been many studies on bidirectional promoters. However, the mechanism by which $\mathrm{H} 2 \mathrm{H}$ genes are regulated at the transcriptional level still needs further clarification, especially with regard to the co-regulation of $\mathrm{H} 2 \mathrm{H}$ pairs. In this study, we first used the $\mathrm{Hi}-\mathrm{C}$ data of chromatin linkages to identify spatially interacting $\mathrm{H} 2 \mathrm{H}$ pairs, and then integrated $\mathrm{Ch} / \mathrm{P}$-seq data to compare $\mathrm{H} 2 \mathrm{H}$ gene pairs with and without evidence of spatial interactions in terms of their binding transcription factors (TFs). Using ChIP-seq and DNase-seq data, histones and DNase associated with $\mathrm{H} 2 \mathrm{H}$ pairs were identified. Furthermore, we looked into the connections between $\mathrm{H} 2 \mathrm{H}$ genes in a human co-expression network.
\end{abstract}

Results: We found that i) Similar to the behaviour of two genes within an $\mathrm{H} 2 \mathrm{H}$ pair (intra- $\mathrm{H} 2 \mathrm{H}$ pair), a gene pair involving two distinct $\mathrm{H} 2 \mathrm{H}$ pairs (inter- $\mathrm{H} 2 \mathrm{H}$ pair) which interact with each other spatially, share common transcription factors (TFs); ii) TFs of intra- and inter-H2H pairs are distributed differently. Factors such as HEY1, GABP, Sin3Ak-20, POL2, E2F6, and C-MYC are essential for the bidirectional transcription of intra-H2H pairs; while factors like CTCF, BDP1, GATA2, RAD21, and POL3 play important roles in coherently regulating inter-H2H pairs; iii) $\mathrm{H} 2 \mathrm{H}$ gene blocks are enriched with hypersensitive DNase and modified histones, which participate in active transcriptions; and iv) $\mathrm{H} 2 \mathrm{H}$ genes tend to be highly connected compared with non- $\mathrm{H} 2 \mathrm{H}$ genes in the human co-expression network.

Conclusions: Our findings shed new light on the mechanism of the transcriptional regulation of $\mathrm{H} 2 \mathrm{H}$ genes through their linear and spatial interactions. For intra- $\mathrm{H} 2 \mathrm{H}$ gene pairs, transcription factors regulate their transcriptions through bidirectional promoters, whereas for inter- $\mathrm{H} 2 \mathrm{H}$ gene pairs, transcription factors are likely to regulate their activities depending on the spatial interaction of $\mathrm{H} 2 \mathrm{H}$ gene pairs. In this way, two distinctive groups of transcription factors mediate intra- and inter- $\mathrm{H} 2 \mathrm{H}$ gene transcriptions respectively, resulting in a highly compact gene regulatory network.

\section{Background}

More than $10 \%$ of human adjacent protein-coding genes are divergently transcribed with their transcription start sites (TSSs) at a distance <1 kb [1-3]. "Head-to-head" $(\mathrm{H} 2 \mathrm{H})$ is used to describe a gene configuration where two adjacent genes are located on opposite strands of DNA and transcribed divergently with TSSs $<1 \mathrm{~kb}$. The sequences between an $\mathrm{H} 2 \mathrm{H}$ gene pair (intra- $\mathrm{H} 2 \mathrm{H}$ pair) are called bidirectional promoters. The region spanning both genes and the bidirectional promoter region is

\footnotetext{
* Correspondence: Jenny.Wei@astrazeneca.com; yyli@scbit.org

${ }^{2}$ AstraZeneca, R\&D Information, 199 Liangjing Road, Building 2, Shanghai 201203, China

'Shanghai Center for Bioinformation Technology, Shanghai, P R China Full list of author information is available at the end of the article
}

regarded as an $\mathrm{H} 2 \mathrm{H}$ block; genes with $\mathrm{H} 2 \mathrm{H}$ organization are called $\mathrm{H} 2 \mathrm{H}$ genes (see Figure $1 \mathrm{~A}$ ). Two distinct $\mathrm{H} 2 \mathrm{H}$ gene pairs comprise an inter-H2H pair (see Figure 1B). Our previous work has reported that $\mathrm{H} 2 \mathrm{H}$ gene pairs are evolutionally conserved, functionally related and coexpressed $[2,3]$. The mechanism of transcriptional regulation of intra- and inter- $\mathrm{H} 2 \mathrm{H}$ gene pairs is still poorly understood and deserves considerable attention.

It is thought that intra- $\mathrm{H} 2 \mathrm{H}$ gene pairs are regulated by bidirectional promoters [4]. But what elements and transcription factors (TFs) play a vital role during the regulation process is still an open question. It is well known that eukaryotic gene expression regulation involves combinatorial control of TFs, which could be organized both in linear and three-dimensional conformations [5]. In

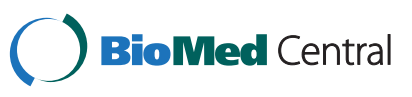




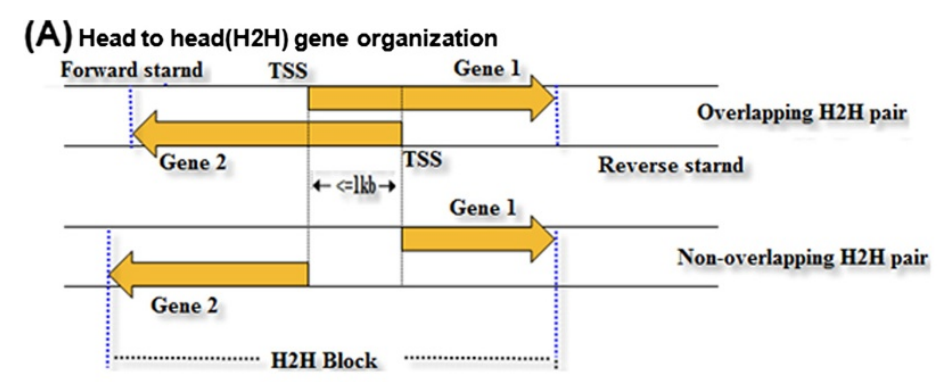

(B) Intra-H2H pair and inter-H2H pairs

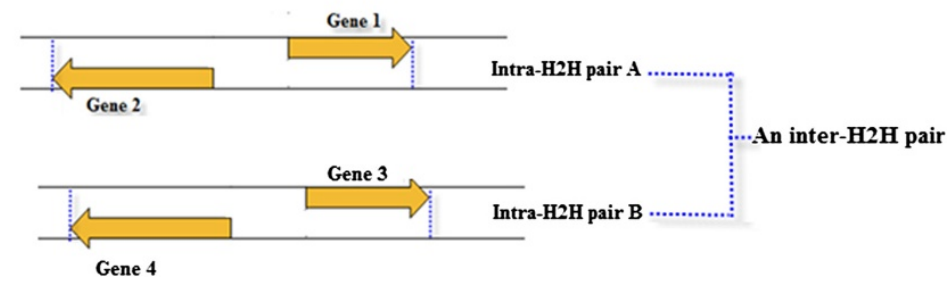

Figure 1 The definition of head to head $(\mathrm{H} 2 \mathrm{H})$ gene organization and intra/inter-H2H pairs. (A) Head to head $(\mathrm{H} 2 \mathrm{H})$ gene organization. The region between the two transcription start sites is called a bidirectional promoter and the region between the ends of two genes is an $\mathrm{H} 2 \mathrm{H}$ block. (B) Intra- $\mathrm{H} 2 \mathrm{H}$ pairs and an inter- $\mathrm{H} 2 \mathrm{H}$ pair. An inter- $\mathrm{H} 2 \mathrm{H}$ pair involves two intra- $\mathrm{H} 2 \mathrm{H}$ gene pairs.

our previous report, there proved to be positive expression correlations among $\mathrm{H} 2 \mathrm{H}$ gene pairs as well as genes within an individual $\mathrm{H} 2 \mathrm{H}$ pair [3]. However, the means by which TF regulations can be accomplished over long distances between inter-gene pairs are unknown. It was hypothesized that the establishment of close contacts or chromatin loops may facilitate the process [6]. Using the new Hi-C technology, spatial proximity maps of the human genome have been built [7]. With ChIP-seq data, TFs and modified histones for $\mathrm{H} 2 \mathrm{H}$ genes can be identified. By using these data, we identified two distinctive groups of transcription factors mediating intra- and inter- $\mathrm{H} 2 \mathrm{H}$ gene transcriptions respectively.

It has been proposed that bidirectional promoters should not be considered under an umbrella classification for one large regulatory network, nor should they be divided into thousands of gene pairs [8]. We hypothesized that such $\mathrm{H} 2 \mathrm{H}$ genes, may contribute to the compactness of the overall gene regulatory network because they are highly co-expressed. Through the construction of human co-expression networks as part of our methodology, we looked into the connections between $\mathrm{H} 2 \mathrm{H}$ genes and non- $\mathrm{H} 2 \mathrm{H}$ genes and compared their attributes.

\section{Results and discussion}

\section{Characterization of TFs for intra- $\mathrm{H} 2 \mathrm{H}$ gene pairs}

In this study, there were 1447 Human $\mathrm{H} 2 \mathrm{H}$ pairs in $\mathrm{DBH} 2 \mathrm{H}$ in total [9] and 45 transcription factors are available by using the public ChIP-seq data in the K562 cell line (see Methods). If the binding sites of one TF overlap with $\mathrm{H} 2 \mathrm{H}$ blocks, the TF is regarded to bind to these $\mathrm{H} 2 \mathrm{H}$ gene pairs. Out of the $1447 \mathrm{H} 2 \mathrm{H}$ pairs, a total of 1308 were identified to bind to the 45 TFs. We defined TFs that bind to more than $45 \%$ of $\mathrm{H} 2 \mathrm{H}$ pairs as overrepresented TFs, of which there were 17 overrepresented TFs identified (see Figure 2). Overrepresented transcription factors such as GABP, POL2, E2F6, E2F4 and c-MYC have been reported in previous studies [4], and transcription factors like HEY1, SIN3AK-20 and SRF were first discovered in our study. As we know, $\mathrm{H} 2 \mathrm{H}$ genes are mainly enriched in biological processes like DNA repair and the cell cycle (see the function enrichment results using DAVID [10] in Additional file 1). Overrepresented TFs are mainly involved in active transcriptional activity or regulating genes in the cell cycle process. GABP is the ubiquitous ets-family transcription factor GA-binding protein. It was reported that GABP binding affinity is associated with bidirectional transcriptional activity in a luciferase transfection assay [11]. POL2 is RNA polymerase II which catalyzes the transcription of DNA to synthesize precursors of mRNA [12]. c-MYC target genes are mainly involved in cell growth, apoptosis and metabolism [13]. The E2F family plays a crucial role in the control of the cell cycle and tumor suppressor protein activities [14]. E2F4 and E2F6 are involved in the cell cycle regulation. According to Gene Ontology (http://www.geneontology.org/), protein HEY1 is an RNA polymerase II core promoter sequence-specific DNA binding transcription factor. SRF is a transcription factor that binds to the serum response element (SRE). This protein regulates the activity of many immediate-early genes, and participates in cell cycle regulation, apoptosis, cell growth, and cell differentiation [15]. 


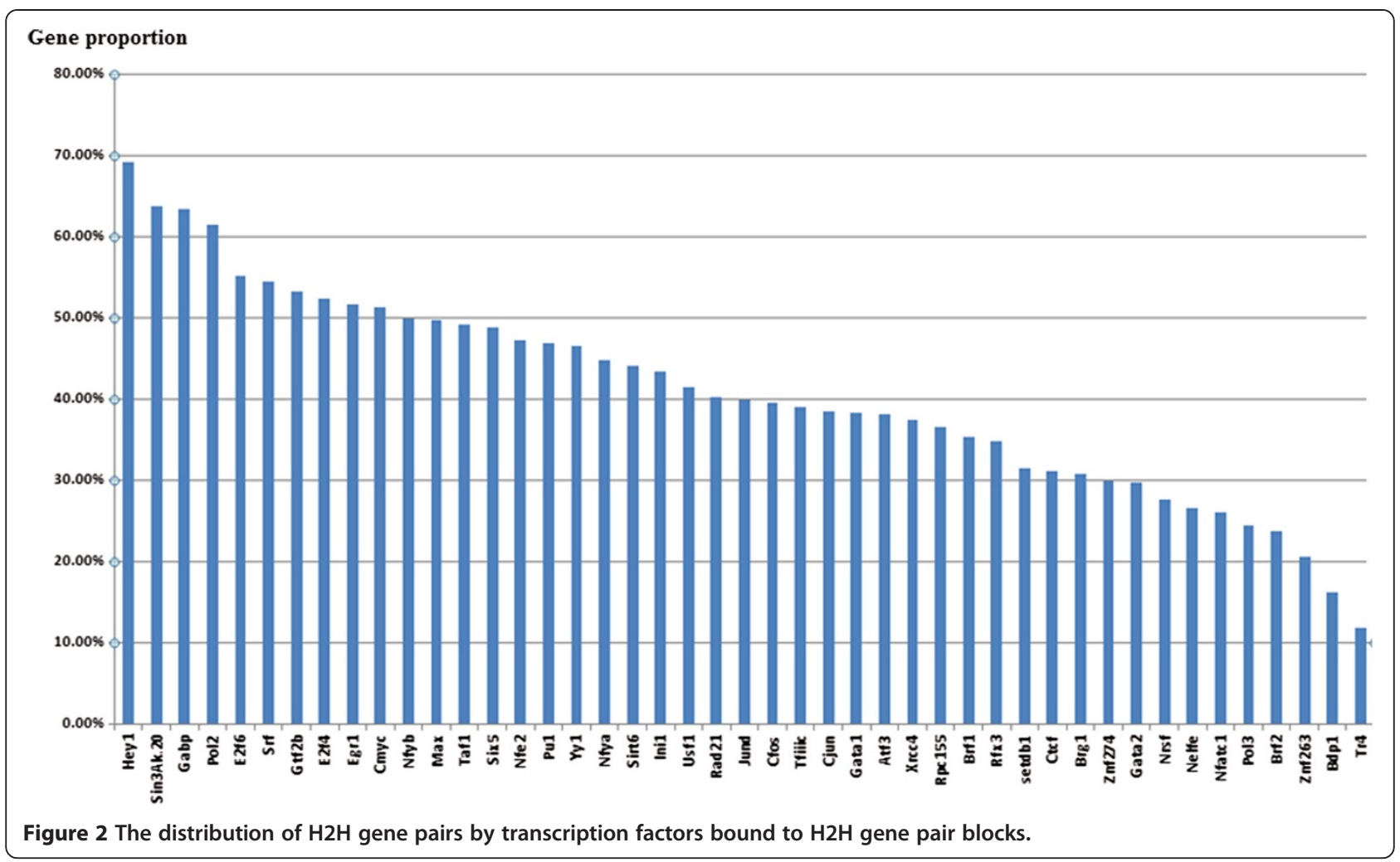

Based on the regulation profile of TFs binding to $\mathrm{H} 2 \mathrm{H}$ gene pairs, we clustered the TF pairs hierarchically using Pearson's correlation coefficient and Ward's method [16]. As shown in Figure 3, 45 TFs were clustered into 2 groups, one group mostly comprised of overrepresented TFs (coloured in Blue) and the other group mostly comprised of non-overrepresented TFs (coloured in Red).

\section{TF interaction network regulating $\mathrm{H} 2 \mathrm{H}$ gene pairs}

Using the transcription factor data described in Methods, we built a binary matrix categorizing whether a given $\mathrm{H} 2 \mathrm{H}$ gene pair is regulated by a given TF. By analyzing the correlation between each TF pair (see Methods), we identified co-occurring TF pairs which bind to the same $\mathrm{H} 2 \mathrm{H}$ gene pairs. Then we constructed a transcription factor interaction network based on TFs' co-occurrence.

As shown in Figure 4, 12 TFs (nodes in yellow) are highly connected to each other, and each of them regulates more than $40 \%$ of all $\mathrm{H} 2 \mathrm{H}$ genes. All these TFs coregulate $\mathrm{H} 2 \mathrm{H}$ genes and most of them are essential for bidirectional promoters in the regulation of intra- $\mathrm{H} 2 \mathrm{H}$ genes. TFs in other small subnets are not included in the overrepresented group. However, based on the evidence in the existing literature, most of these TFs are heavily involved in spatial interactions. One subnet is composed of two TFs including CTCF-RAD21 and another subnet is made up of GATA1-GATA2. Recent genome-wide assays have shown that the transcription

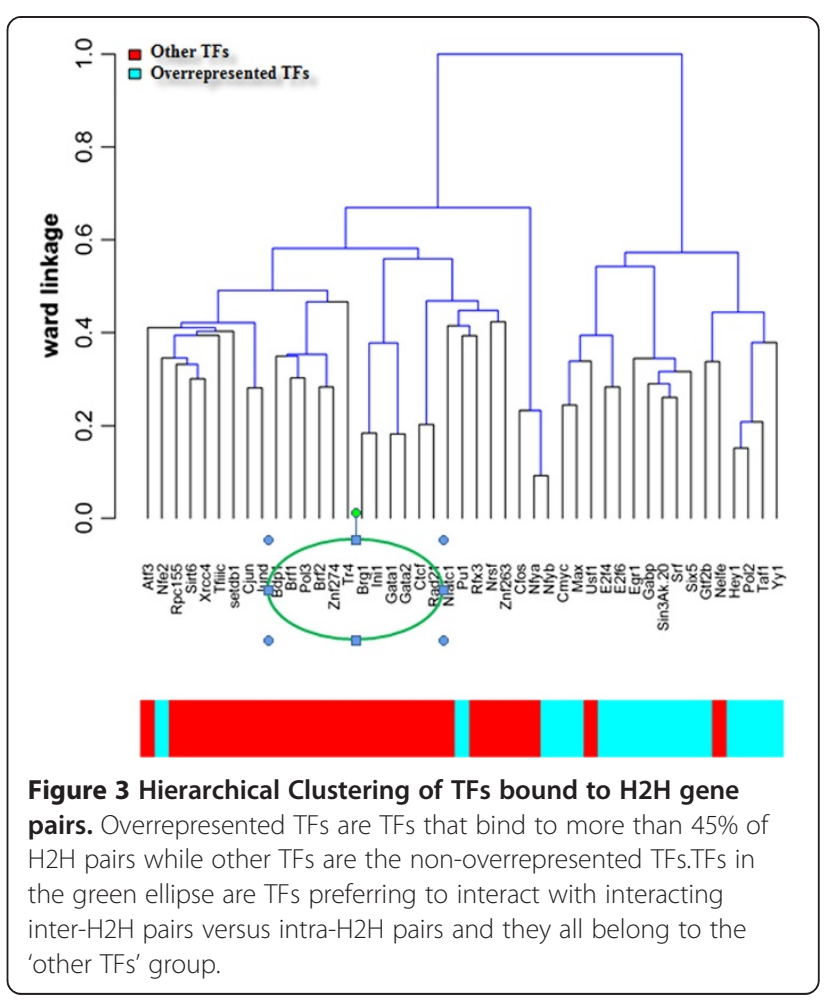




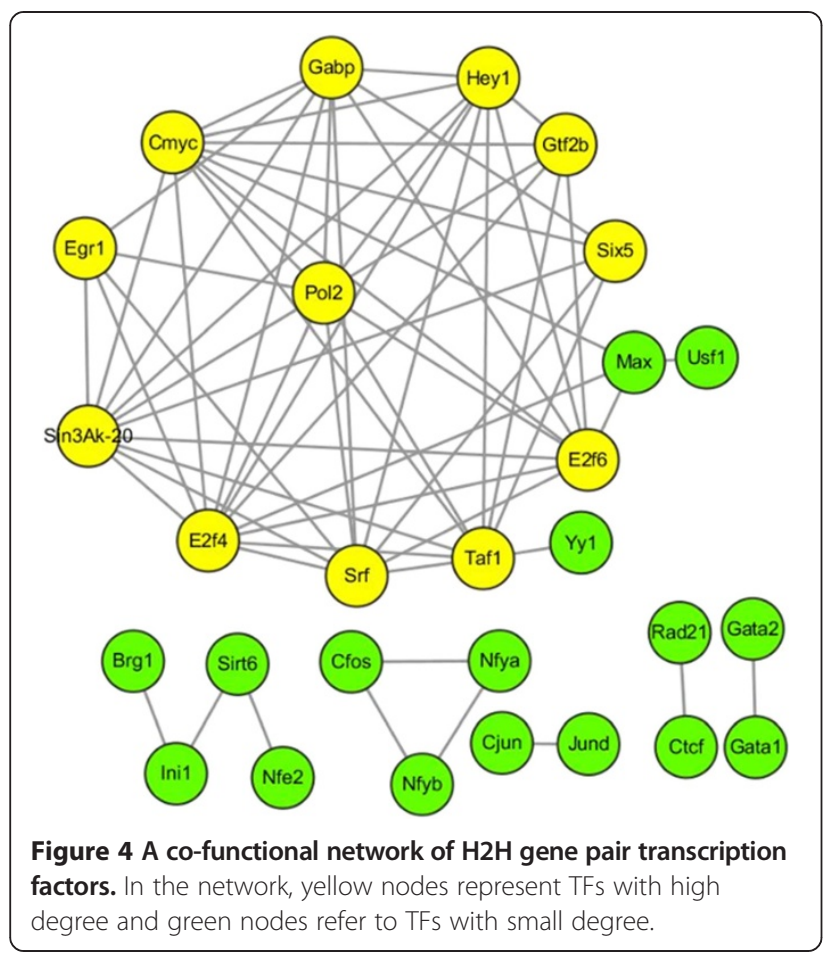

factor CTCF can link chromatin domains through longrange interactions between distal genomic regions, suggesting its crucial role as an architect of chromatin conformation. CTCF/RAD21 mediated insulators maintain the chromatin loop formation and the localization of transcriptional apparatuses at the promoters, suggesting the essential role of chromatin insulation in controlling the expression of clustered genes [17]. GATA was demonstrated to regulate genes remotely. The knockdown of GATA1 and GATA2 altered the expressions of genes close to GATA linearly and spatially [18]. BRG1, connected with other TFs in the subnet (BRG1Ini1-Sirt6-Nfe2), is a protein required for the long-range interaction of a locus control region with a downstream promoter [19]. TFs Cjun and JunD are connected in the TF interaction network. Cjun, in combination with c-Fos, forms the AP-1 early response transcription factor; and JunD is a functional component of the AP1 transcription factor complex [20]. It is reported that long-range transcription controls of Ap- 1 factors play a role in the regulation of the gene PAD/3 [21].

Since TFs can bridge both promoters and distal cisregulatory elements such as enhancers, insulators, and silencers while looping out of the intervening DNA [17], we looked into the TF distributions in spatially interacting inter- $\mathrm{H} 2 \mathrm{H}$ pairs.

\section{Inter- $\mathrm{H} 2 \mathrm{H}$ gene pairs involved in $\mathrm{Hi}-\mathrm{C}$ supported interaction loci}

Using interacting genomic regions from $\mathrm{Hi}-\mathrm{C}$ data [18], we mapped $\mathrm{H} 2 \mathrm{H}$ gene blocks to long-range interacting loci and identified inter- $\mathrm{H} 2 \mathrm{H}$ genes involved in spatial interactions (see Methods). If both of the interacting loci overlapped with different $\mathrm{H} 2 \mathrm{H}$ blocks, the two $\mathrm{H} 2 \mathrm{H}$

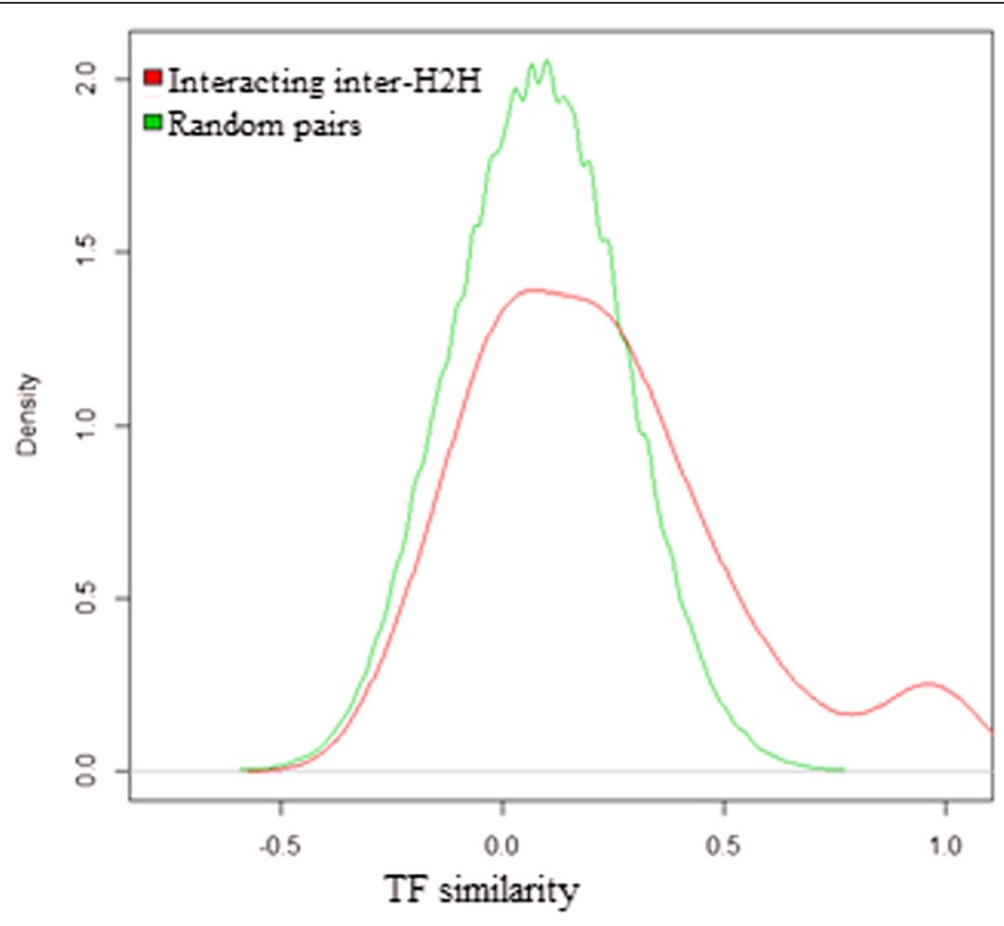

Figure 5 TF similarity distribution of interacting inter- $\mathrm{H} 2 \mathrm{H}$ pairs and random inter-gene pairs. 
Table 1 Percentage of TFs detected in intra- $\mathrm{H} 2 \mathrm{H}$ gene pairs and interacting inter- $\mathrm{H} 2 \mathrm{H}$ pairs

\begin{tabular}{|c|c|c|c|}
\hline TFs & Intra- $\mathrm{H} 2 \mathrm{H}$ pairs & Interacting inter-H2H pairs & Enrichment (fold change) \\
\hline Bdp1 & $14.7 \%$ & $40 \%$ & 2.72 \\
\hline Ctcf & $28.2 \%$ & $60 \%$ & 2.13 \\
\hline Brf2 & $21.5 \%$ & $45.7 \%$ & 2.12 \\
\hline Nfatc1 & $23.6 \%$ & $49.5 \%$ & 2.10 \\
\hline Brg1 & $27.9 \%$ & $58.1 \%$ & 2.08 \\
\hline Znf274 & $27.0 \%$ & $56.2 \%$ & 2.08 \\
\hline Gata2 & $26.9 \%$ & $55.2 \%$ & 2.05 \\
\hline Tr4 & $10.7 \%$ & $21.9 \%$ & 2.04 \\
\hline Znf263 & $18.6 \%$ & $38.1 \%$ & 2.04 \\
\hline Nrsf & $25 \%$ & $50.5 \%$ & 2.02 \\
\hline Cjun & $34.8 \%$ & $69.5 \%$ & 2.00 \\
\hline Pol3 & $22.1 \%$ & $42.9 \%$ & 1.94 \\
\hline $\mathrm{Rfx} \times 3$ & $31.5 \%$ & $60 \%$ & 1.90 \\
\hline Rpc155 & $33 \%$ & $62.9 \%$ & 1.90 \\
\hline Jund & $36.1 \%$ & $68.6 \%$ & 1.90 \\
\hline Gata1 & $34.6 \%$ & $64.8 \%$ & 1.87 \\
\hline Nelfe & $24 \%$ & $44.8 \%$ & 1.87 \\
\hline Rad21 & $36.5 \%$ & $67.6 \%$ & 1.85 \\
\hline Atf3 & $34.5 \%$ & $63.8 \%$ & 1.85 \\
\hline Ini1 & $39.2 \%$ & $72.4 \%$ & 1.84 \\
\hline Yy1 & $42.1 \%$ & $77.1 \%$ & 1.83 \\
\hline Max & $45.1 \%$ & $82 \%$ & 1.82 \\
\hline Cfos & $35.8 \%$ & $63.8 \%$ & 1.78 \\
\hline Pu1 & $42.5 \%$ & $75.2 \%$ & 1.77 \\
\hline Tfiiic & $35.2 \%$ & $61.9 \%$ & 1.76 \\
\hline Sirt6 & $39.9 \%$ & $69.5 \%$ & 1.74 \\
\hline Brf1 & $31.9 \%$ & $54.3 \%$ & 1.70 \\
\hline Nfya & $40.6 \%$ & $68.6 \%$ & 1.69 \\
\hline Nfyb & $45.1 \%$ & $76.2 \%$ & 1.69 \\
\hline Xrcc4 & $33.9 \%$ & $57.1 \%$ & 1.69 \\
\hline Six 5 & $44.2 \%$ & $74.3 \%$ & 1.68 \\
\hline Taf1 & $44.5 \%$ & $74.3 \%$ & 1.67 \\
\hline E2f4 & $47.4 \%$ & $78.1 \%$ & 1.65 \\
\hline Setdb1 & $28.5 \%$ & $46.7 \%$ & 1.64 \\
\hline $\mathrm{Nfe} 2$ & $42.8 \%$ & $69.5 \%$ & 1.63 \\
\hline Cmyc & $46.4 \%$ & $74.3 \%$ & 1.60 \\
\hline Usf1 & $37.6 \%$ & $60 \%$ & 1.60 \\
\hline Egr1 & $46.7 \%$ & $74.3 \%$ & 1.59 \\
\hline Srf & $49.3 \%$ & $78.1 \%$ & 1.58 \\
\hline Pol2 & $55.6 \%$ & $86.7 \%$ & 1.56 \\
\hline E2f6 & $49.9 \%$ & $76.2 \%$ & 1.53 \\
\hline Hey1 & $62.6 \%$ & $92.4 \%$ & 1.48 \\
\hline Gtf2b & $48.2 \%$ & $70.5 \%$ & 1.46 \\
\hline Gabp & $57.4 \%$ & $82.9 \%$ & 1.44 \\
\hline Sin $3 A k-20$ & $57.6 \%$ & $82.9 \%$ & 1.44 \\
\hline
\end{tabular}

The proportion of intra- or inter- pairs bound by one TF is the number of intra-/inter- pairs bound by one TF divided by the total number of intra- or inter- pairs. 
pairs (an 'inter-H2H'pair) were annotated to be spatially interacting with each other. In this way, a total of 105 interacting 'inter-H2H' pairs with $\mathrm{Hi}-\mathrm{C}$ evidence were selected (see Additional file 2). To identify the characteristics of those inter- $\mathrm{H} 2 \mathrm{H}$ pairs, we compared the TF similarities between interacting inter- $\mathrm{H} 2 \mathrm{H}$ pairs and random inter-pairs. A "random inter-pair" are two human genes randomly picked out from all the human genes. The interacting inter-pairs had higher TF similarity scores (see Methods) than random inter-pairs (see Figure 5). The average TF similarity score for interacting inter-pairs is 0.221 while it is 0.079 for random inter-pairs. The result indicates that the spatial interaction of inter- $\mathrm{H} 2 \mathrm{H}$ genes may be associated with the shared transcription factors.

As shown in Table 1, TFs are ranked by fold changes calculated according to the proportions of TFs binding to inter- $\mathrm{H} 2 \mathrm{H}$ pairs compared with TFs binding to intra$\mathrm{H} 2 \mathrm{H}$ pairs. The top TFs with a fold change $>2$ are BDP1, CTCF, GATA2, BRF1, ZNF274, BRF2. It seems that these TFs may have a stronger preference for binding to inter- $\mathrm{H} 2 \mathrm{H}$ vs. intra- $\mathrm{H} 2 \mathrm{H}$. They were clustered in the group marked Red in Figure 3 and differed from the group of overrepresented TFs for bidirectional promoters marked Blue. Some of these TFs in the Red group are indicated in the literature to mediate spatial interactions. CTCF mediates both intra- and inter-chromosomal interactions [22]. ZNF274 is involved in the recruitment of KAP1 and SETDB1 to specific regions [23]. BRF2, encoding one of the subunits of RNA polymerase III transcription factor complex, is a general activator of RNA polymerase III transcription [24]; and many POL3transcribed genes are found spatially clustered at or near the nucleolus [25]. We infer that other TFs enriched in interacting inter- $\mathrm{H} 2 \mathrm{H}$ pairs and clustered with those reported TFs (see green ellipse in Figure 3) may also mediate spatial interactions.

The $\mathrm{Hi}-\mathrm{C}$ results indicate that intra- and inter- $\mathrm{H} 2 \mathrm{H}$ pairs show different transcriptional regulation profiles. The TFs of $\mathrm{H} 2 \mathrm{H}$ genes can be separated into 2 groups.
One group (marked Blue in Figure 3) mainly regulates linear intra- $\mathrm{H} 2 \mathrm{H}$ gene pairs and the other (marked Red in Figure 3) is involved in the spatial regulation of inter$\mathrm{H} 2 \mathrm{H}$ pairs. Transcription factors such as GABP, POL2, SRF, SIN2AK-20, HEY1 and c-MYC regulate bidirectional transcription and are enriched in intra- $\mathrm{H} 2 \mathrm{H}$ gene pairs, while other factors such as CTCF, BDP1 and ZNF274 play important roles in spatial interactions between $\mathrm{H} 2 \mathrm{H}$ pairs.

\section{Modified histones and hypersensitive DNase bound to $\mathrm{H} 2 \mathrm{H}$ gene pairs}

1384 of the $1447 \mathrm{H} 2 \mathrm{H}$ pairs are associated with the 9 histones and DNase. The distribution of histones and DNase bound to $\mathrm{H} 2 \mathrm{H}$ pairs is described in Table 2. Hypersensitive DNase, H3K4me2, H3K4me3, H3K9ac and $\mathrm{H} 3 \mathrm{~K} 27 \mathrm{ac}$, which are related to transcriptional activation, bind to $>=80 \% \mathrm{H} 2 \mathrm{H}$ pairs; while $\mathrm{H} 3 \mathrm{~K} 27 \mathrm{me} 3$ and H3K9me3, which are associated with gene silencing [26], are only bound to a small fraction of $\mathrm{H} 2 \mathrm{H}$ gene pairs. Compared to the background genes, a higher proportion of $\mathrm{H} 2 \mathrm{H}$ gene pairs bind to a number of epigenetic markers, such as hypersensitive DNase, H3K4me2, H3K4me3, H3K9ac and H3K27ac (see Table 2, p < 0.01 using Chi-square test). Previous studies have reported that H3K4me3 islands overlap with about $85 \%$ of active genes (expressed genes) while overlapping with $59 \%$ of silent genes (non-expressed genes); H3K27me3 and H3K9me3 protein levels were much higher at silent promoters than at active promoters [27]. The above data suggest that $\mathrm{H} 2 \mathrm{H}$ gene pairs, bound by modified histones of transactional activation, should be highly expressed. An analysis of whole genome microarray data validated that $68 \%$ of $\mathrm{H} 2 \mathrm{H}$ genes are transcribed compared to only $44 \%$ of all human genes [4].

The role of $\mathrm{H} 2 \mathrm{H}$ genes in Human co-expression network Since inter- $\mathrm{H} 2 \mathrm{H}$ gene pairs interact spatially and $\mathrm{H} 2 \mathrm{H}$ gene pairs are biologically important, we speculate as

Table 2 The proportion of hypersensitive DNase and modified histones bound to $\mathrm{H} 2 \mathrm{H}$ pairs

\begin{tabular}{llll}
\hline Epigenetic markers & $\begin{array}{l}\text { \#H2H pairs with } \\
\text { epigenetic markers }\end{array}$ & $\begin{array}{l}\text { Proportion of H2H with } \\
\text { epigenetic markers }\end{array}$ & $\begin{array}{l}\text { Proportion of all genes } \\
\text { with epigenetic markers }\end{array}$ \\
\hline H3K4me2 & 1221 & $84.38 \%$ & $48.92 \%$ \\
H3K4me3 & 1218 & $84.17 \%$ & $47.86 \%$ \\
H3K9ac & 1174 & $81.13 \%$ & $43.47 \%$ \\
H3K27ac & 1148 & $79.34 \%$ & $42.30 \%$ \\
H3K4me1 & 986 & $68.14 \%$ & $41.39 \%$ \\
H3K36me3 & 784 & $54.18 \%$ & $29.37 \%$ \\
H4K20me1 & 687 & $47.48 \%$ & $31.06 \%$ \\
H3K27me3 & 199 & $13.75 \%$ & $17.13 \%$ \\
H3K9me3 & 63 & $4.35 \%$ & $4.84 \%$ \\
\hline
\end{tabular}




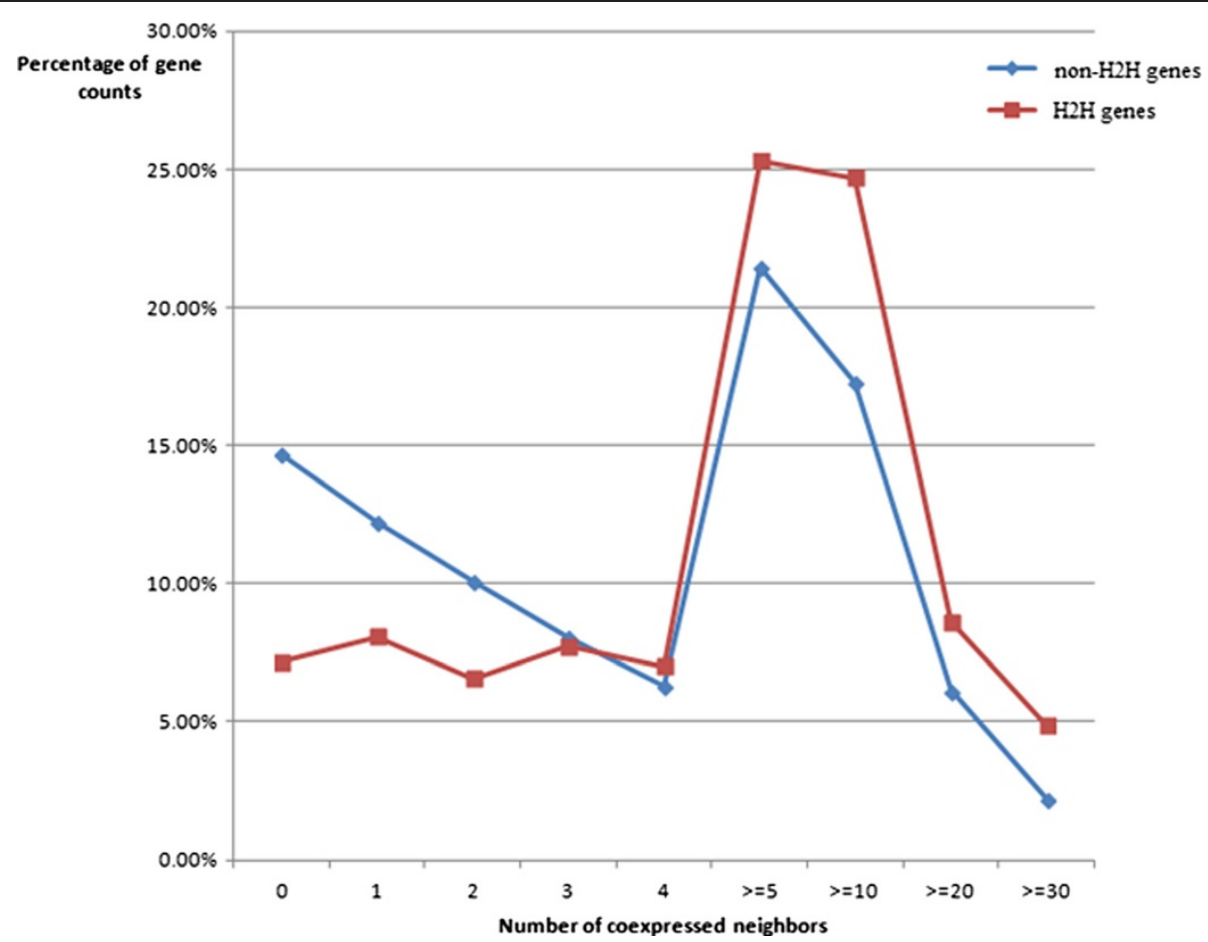

Figure 6 Percentage of gene counts by number of co-expressed neighbors. $\mathrm{Non}-\mathrm{H} 2 \mathrm{H}$ genes are genes without $\mathrm{H} 2 \mathrm{H}$ gene organization.

to whether $\mathrm{H} 2 \mathrm{H}$ genes are also highly connected to other genes. In this work, we constructed a human co-expression network of 20280 genes (see Methods) and calculated the number of co-expressed neighbours of each gene. The percentage of gene counts by number of co-expressed neighbours is shown in Figure 6. As it makes clear, $\mathrm{H} 2 \mathrm{H}$ genes exhibited higher connectivity than non- $\mathrm{H} 2 \mathrm{H}$ genes. The average numbers of coexpressed neighbours for $\mathrm{H} 2 \mathrm{H}$ genes and non- $\mathrm{H} 2 \mathrm{H}$ genes are 7 vs. 4 (median) or 9.8 vs. 7.6 (mean). The Wilcoxon signed-rank test showed the difference between the two groups ( $\mathrm{H} 2 \mathrm{H}$ genes vs. non- $\mathrm{H} 2 \mathrm{H}$ genes) was statistically significant ( $\mathrm{p}$-value $<2.2 \mathrm{e}-16$ ). We also randomly selected genes equal to the number of $\mathrm{H} 2 \mathrm{H}$ genes from all genes in the network to compare the amount of coexpressed neighbors between the two groups, repeating this function 10000 times. $\mathrm{H} 2 \mathrm{H}$ genes still showed a higher average connectivity each time (see Additional file 3 ). From the above result, we conclude that it is likely that $\mathrm{H} 2 \mathrm{H}$ genes are highly connected with other genes (not only $\mathrm{H} 2 \mathrm{H}$ genes) in a human co-expression network.

It was reported that co-expressed genes tend to be coregulated by one or more common transcription factors [28]. Since $\mathrm{H} 2 \mathrm{H}$ genes tend to be highly connected to other genes in the co-expression network and have distinctive groups of transcription factors mediating intraand inter- $\mathrm{H} 2 \mathrm{H}$ gene transcriptions, we propose that $\mathrm{H} 2 \mathrm{H}$ genes contribute to the compactness of the overall gene regulatory network.

\section{Conclusions}

A systematic investigation of $\mathrm{H} 2 \mathrm{H}$ genes, their transcription factors and the histones and DNase bound to them based on human genome Hi-C, ChIP-seq and DNase-seq data was conducted in this study. We echoed and adjusted several known properties of $\mathrm{H} 2 \mathrm{H}$ gene organization and also provided new observations on the spatial regulation of $\mathrm{H} 2 \mathrm{H}$ genes. We further demonstrated that $\mathrm{H} 2 \mathrm{H}$ intrapairs and inter-pairs are regulated by two distinct groups of transcription factors. The binding of hypersensitive DNase and the modified histones associated with active transcription may facilitate the high expression of $\mathrm{H} 2 \mathrm{H}$ genes. Finally, we analysed the properties of $\mathrm{H} 2 \mathrm{H}$ genes in a human co-expression network and found that $\mathrm{H} 2 \mathrm{H}$ genes tend to be highly connected to other genes. We propose that the highly expressed $\mathrm{H} 2 \mathrm{H}$ genes, regulated through both linear and spatial interactions, contribute to the compactness and thus the high efficiency of the entire gene regulatory network.

\section{Methods}

Data sources

$\mathrm{H} 2 \mathrm{H}$ gene pair information was obtained from our previous work: $\mathrm{DBH} 2 \mathrm{H}$ [9]. $\mathrm{DBH} 2 \mathrm{H}$ contains information about $\mathrm{H} 2 \mathrm{H}$ gene pairs from species Human, Mouse, Rat, Chicken and Fugu. There are $1447 \mathrm{H} 2 \mathrm{H}$ pairs in the $\mathrm{DBH} 2 \mathrm{H}$ database. Human gene co-expression data was obtained from COXPRESdb [29]. COXPRESdb is a database of co-expressed gene sets. Gene expression profiles 
of humans in the database are from NCBI GEO, based on the Affymetrix GeneChip (Human Genome U133 Plus 2.0 Array). Genomic interaction regions calculated by Xun Lan et al. were derived from an $\mathrm{Hi}-\mathrm{C}$ data set in K562 cell line [7] using the Mixture Poisson Regression Model and a power-law decay distribution [18].

DNase-seq data for DNase hypersensitivity and ChIP-seq data for 9 modified histones and 45 transcription factors in the K562 cell line were downloaded from UCSC (http://genome.ucsc.edu/encode/dataMatrix/encodeDataMatrixHuman. html). The data were analyzed using W-ChIPeaks (http:// motif.bmi.ohio-state.edu/W-ChIPeaks) [18,30].

\section{Identification of interacting inter- $\mathrm{H} 2 \mathrm{H}$ pairs}

We integrated the location data of human $\mathrm{H} 2 \mathrm{H}$ blocks with genomic interaction loci from $\mathrm{Hi}$-C. If a locus overlapped with a $\mathrm{H} 2 \mathrm{H}$ block, we annotated the locus with the $\mathrm{H} 2 \mathrm{H}$ pair. If both of the interacting loci overlapped with different $\mathrm{H} 2 \mathrm{H}$ blocks, the two $\mathrm{H} 2 \mathrm{H}$ pairs (an inter$\mathrm{H} 2 \mathrm{H}$ 'pair) were regarded to be spatially interacting with each other. A total of 546 pairs of interacting loci were fully annotated by $\mathrm{H} 2 \mathrm{H}$ pairs, and among them, 105 pairs of interacting loci were annotated by different $\mathrm{H} 2 \mathrm{H}$ pairs ('inter-H2H' pairs) (see Additional file 2).

\section{Histone modifications and transcription factors for $\mathrm{H} 2 \mathrm{H}$ genes}

In this paper we studied 45 transcription factors, 9 different types of histone modifications as well as DNase hypersensitive sites. TFs, modified histones and DNase with binding sites overlapping with $\mathrm{H} 2 \mathrm{H}$ blocks were identified and annotated with $\mathrm{H} 2 \mathrm{H}$ pairs for further analysis. For an interacting 'inter- $\mathrm{H} 2 \mathrm{H}$ ' pair, TFs bound to either $\mathrm{H} 2 \mathrm{H}$ pair were regarded as binding to the 'inter$\mathrm{H} 2 \mathrm{H}^{\prime}$ pair. The distributions as well as the preferences of transcriptional factors and epigenetic markers bound to $\mathrm{H} 2 \mathrm{H}$ pairs were investigated. To assess the bindings of epigenetic markers to background genes (all the $25363 \mathrm{hu}$ man genes from UCSC hg18), we used each human gene region plus its 100 bp bases before transcription start site to map to the binding sites of modified histones and DNase. We also compared TF similarities between interacting inter- $\mathrm{H} 2 \mathrm{H}$ pairs and random inter-pairs to study the characteristics of their spatial interactions. Here, the TF similarity between an inter-gene pair is represented as the ratio of the shared TFs to the total TFs binding to the same inter-gene pair.

\section{Construction of co-functional networks by transcription factors}

We obtained a binary regulation matrix of transcription factors and $\mathrm{H} 2 \mathrm{H}$ genes after completing the above analysis (see Additional file 4). The matrix rows represent transcription factors and the columns represent $\mathrm{H} 2 \mathrm{H}$ gene pairs. Each element of the matrix indicates the binding of a transcription factor to an $\mathrm{H} 2 \mathrm{H}$ gene pair. 1 represents a transcription factor binding to an $\mathrm{H} 2 \mathrm{H}$ pair, 0 represents a transcription factor not binding to an $\mathrm{H} 2 \mathrm{H}$ pair. Then we analyzed the co-occurrence of each transcription factor pair regulating at least 10 gene pairs. P-value was calculated to evaluate the statistical significance of co-occurrence using a binomial test. The overlapping ratio between a pair of two transcription factors was calculated as: number of shared $\mathrm{H} 2 \mathrm{H}$ pairs regulated by a TF pair/total number of $\mathrm{H} 2 \mathrm{H}$ pairs bound to a TF pair. We defined transcription factor pair co-occurrence as a calculated $\mathrm{p}$-value $<0.01$ and the overlapping ratio $>0.6$. A co-occurrence network of transcription factors that regulate $\mathrm{H} 2 \mathrm{H}$ genes was visualized using Cytoscape 3.0.2 [31].

\section{Human co-expression network}

COXPRESdb provides the co-expression data of 20280 human genes including Pearson's correlation coefficient (PCC) of gene expression profiles and a relative correlation index: mutual rank (MR) for each gene [32]. Mutual rank (MR) is a geometric average of the PCC rank from gene $\mathrm{A}$ to gene $\mathrm{B}$ and that of gene $\mathrm{B}$ to gene $\mathrm{A}$ and is considered a standard measure of the biological significance of gene co-expression. Here, we considered gene pairs with $M R<=20$ as co-expressed pairs. We constructed a global human gene co-expression network based on the co-expressed pairs and singleton genes (without co-expressed genes) from this database.

\section{Additional files}

Additional file 1: Functional annotation for $\mathrm{H} 2 \mathrm{H}$ genes. The function
enrichment results for $\mathrm{H} 2 \mathrm{H}$ genes using DAVID are listed in the table.
Additional file 2: Inter- $\mathrm{H} 2 \mathrm{H}$ pairs with spatial interaction. Using
interacting genomic regions from $\mathrm{Hi}-\mathrm{C}$ data, 105 inter- $\mathrm{H} 2 \mathrm{H}$ pairs with
spatial interactions were identified (see the first sheet). And the detailed
$\mathrm{H} 2 \mathrm{H}$ pair information is also provided on another sheet.
Additional file 3: The distribution of the average number of co-expressed
neighbours of the randomized genes in the co-expression network. The
red line represents the mean number of co-expressed neighbors of $\mathrm{H} 2 \mathrm{H}$
genes and the black curve is the distribution of the average number of
co-expressed neighbors of randomized genes.
Additional file $\mathbf{4 :}$ : A binary matrix of TFs regulating $\mathrm{H} 2 \mathrm{H}$ gene. $\mathrm{A}$
binary regulation matrix of transcription factors (TFs) and $\mathrm{H} 2 \mathrm{H}$ genes is
provided in sheet 1 . Row names are $\mathrm{H} 2 \mathrm{H}$ gene pairs, column names are
TFs. The value of the matrix indicates whether a transcription factor is
binding to an $\mathrm{H} 2 \mathrm{H}$ gene pair. 1 represents a transcription factor binding to
an $\mathrm{H} 2 \mathrm{H}$ pair, 0 represents a transcription factor not binding to an $\mathrm{H} 2 \mathrm{H}$ pair.

\section{Abbreviations}

TF: Transcriptional factor; H2H: Head-to-head; PCC: Pearson's correlation coefficient; MR: Mutual rank.

\section{Competing interests}

The authors declare that they have no competing interests. 


\section{Authors' contributions}

YYL and YQC designed the methodology and conceived this study. YQC performed analysis and participated in writing the manuscript. JW and YXL participated in writing the manuscript. All authors have read and approved the final manuscript.

\section{Acknowledgements}

The authors want to thank Dr. Hui Yu and Dr. Xiao Dong from SIBS for helpful suggestion. This work was supported by grants from National Key Basic Research Program (grant numbers: 2014DFB30020, 2013CB910801, 2012CB316501) and National Natural Science Foundation of China (31171268).

\section{Author details}

${ }^{1}$ Shanghai Center for Bioinformation Technology, Shanghai, P R China. ${ }^{2}$ AstraZeneca, R\&D Information, 199 Liangjing Road, Building 2, Shanghai 201203, China. ${ }^{3}$ Key Lab of Systems Biology, Shanghai Institutes for Biological Sciences, Chinese Academy of Sciences, Shanghai, P R China.

Received: 27 March 2014 Accepted: 19 June 2014

Published: 24 June 2014

\section{References}

1. Trinklein ND, Aldred SF, Hartman SJ, Schroeder DI, Otillar RP, Myers RM: An abundance of bidirectional promoters in the human genome. Genome Res 2004, 14(1):62-66.

2. Li YY, Yu H, Guo ZM, Guo TQ, Tu K, Li YX: Systematic analysis of head-to-head gene organization: evolutionary conservation and potential biological relevance. PLoS Comput Biol 2006, 2(7):e74.

3. Chen YQ, YU H, Li YX, Li YY: Sorting out inherent features of head-to-head gene pairs by evolutionary conservation. BMC bioinformatics 2010, 11 Suppl 11:S16.

4. Lin JM, Collins PJ, Trinklein ND, Fu Y, Xi H, Myers RM, Weng Z: Transcription factor binding and modified histones in human bidirectional promoters. Genome Res 2007, 17(6):818-827.

5. Remenyi A, Scholer HR, Wilmanns M: Combinatorial control of gene expression. Nat Struct Mol Biol 2004, 11(9):812-815.

6. Dean $A$ : In the loop: long range chromatin interactions and gene regulation. Brief Funct Genomics 2011, 10(1):3-10.

7. Lieberman-Aiden E, van Berkum NL, Williams L, Imakaev M, Ragoczy T, Telling A, Amit I, Lajoie BR, Sabo PJ, Dorschner MO, Sandstrom R, Bernstein B, Bender MA, Groudine M, Gnirke A, Stamatoyannopoulos J, Mirny LA, Lander ES, Dekker J: Comprehensive mapping of long-range interactions reveals folding principles of the human genome. Science 2009, 326(5950):289-293.

8. Yang MQ, Koehly LM, Elnitski LL: Comprehensive annotation of bidirectional promoters identifies co-regulation among breast and ovarian cancer genes. PLOS Comput Biol 2007, 3(4):e72.

9. $Y u$ H, Yu FD, Zhang GQ, Shen $X$, Chen YQ, Li YY, Li YX: DBH2H: vertebrate head-to-head gene pairs annotated at genomic and post-genomic levels. Database (Oxford) 2009, 2009:bap006.

10. da Huang W, Sherman BT, Lempicki RA: Systematic and integrative analysis of large gene lists using DAVID bioinformatics resources. Nat Protoc 2009, 4(1):44-57.

11. Collins PJ, Kobayashi Y, Nguyen L, Trinklein ND, Myers RM: The ets-related transcription factor GABP directs bidirectional transcription. PLOS Genet 2007, 3(11):e208.

12. Sims RJ 3rd, Mandal SS, Reinberg D: Recent highlights of RNA-polymeraseII-mediated transcription. Curr Opin Cell Biol 2004, 16(3):263-271.

13. Dang CV: C-Myc target genes involved in cell growth, apoptosis, and metabolism. Mol Cell Biol 1999, 19(1):1-11.

14. Stevens C, La Thangue NB: E2F and cell cycle control: a double-edged sword. Arch Biochem Biophys 2003, 412(2):157-169.

15. Schratt G, Weinhold B, Lundberg AS, Schuck S, Berger J, Schwarz H, Weinberg RA, Ruther $U$, Nordheim A: Serum response factor is required for immediate-early gene activation yet is dispensable for proliferation of embryonic stem cells. Mol Cell Biol 2001, 21(8):2933-2943.

16. Ward JH Jr: Hierarchical grouping to optimize an objective function. J Am Stat Assoc 1963, 58(301):236-244.

17. Lee BK, lyer VR: Genome-wide studies of CCCTC-binding factor (CTCF) and cohesin provide insight into chromatin structure and regulation. J Biol Chem 2012, 287(37):30906-30913.
18. Lan X, Witt H, Katsumura K, Ye Z, Wang Q, Bresnick EH, Farnham PJ, Jin VX: Integration of $\mathrm{Hi}-\mathrm{C}$ and $\mathrm{ChIP}$-seq data reveals distinct types of chromatin linkages. Nucleic Acids Res 2012, 40(16):7690-7704.

19. Kim SI, Bultman SJ, Kiefer CM, Dean A, Bresnick EH: BRG1 requirement for long-range interaction of a locus control region with a downstream promoter. Proc Natl Acad Sci U S A 2009, 106(7):2259-2264.

20. Kim J, Woolridge S, Biffi R, Borghi E, Lassak A, Ferrante P, Amini S, Khalili K, Safak M: Members of the AP-1 family, c-Jun and c-Fos, functionally interact with JC virus early regulatory protein large T antigen. J Virol 2003, 77(9):5241-5252.

21. Chavanas S, Adoue V, Mechin MC, Ying S, Dong S, Duplan H, Charveron M, Takahara H, Serre G, Simon M: Long-range enhancer associated with chromatin looping allows AP-1 regulation of the peptidylarginine deiminase 3 gene in differentiated keratinocyte. PLoS One 2008, 3(10):e3408.

22. Splinter E, Heath H, Kooren J, Palstra RJ, Klous P, Grosveld F, Galjart N, de Laat W: CTCF mediates long-range chromatin looping and local histone modification in the beta-globin locus. Genes Dev 2006, 20(17):2349-2354.

23. Frietze $S, O^{\prime} G$ een $H$, Blahnik KR, Jin VX, Farnham PJ: ZNF274 recruits the histone methyltransferase SETDB1 to the $3^{\prime}$ ends of ZNF genes. PLOS One 2010, 5(12):e15082

24. Cabart P, Murphy S: BRFU, a TFIIB-like factor, is directly recruited to the TATA-box of polymerase III small nuclear RNA gene promoters through its interaction with TATA-binding protein. J Biol Chem 2001 276(46):43056-43064.

25. Haeusler RA, Engelke DR: Spatial organization of transcription by RNA polymerase III. Nucleic Acids Res 2006, 34(17):4826-4836.

26. Kouzarides T: Chromatin modifications and their function. Cell 2007, 128(4):693-705.

27. Barski A, Cuddapah S, Cui K, Roh TY, Schones DE, Wang Z, Wei G, Chepelev I, Zhao K: High-resolution profiling of histone methylations in the human genome. Cell 2007, 129(4):823-837.

28. Allocco DJ, Kohane IS, Butte AJ: Quantifying the relationship between co-expression, co-regulation and gene function. BMC bioinformatics 2004, 5:18.

29. Obayashi T, Okamura Y, Ito S, Tadaka S, Motoike IN, Kinoshita K: COXPRESdb: a database of comparative gene coexpression networks of eleven species for mammals. Nucleic Acids Res 2013, 41(Database issue):D1014-D1020.

30. Lan X, Bonneville R, Apostolos J, Wu W, Jin VX: W-ChIPeaks: a comprehensive web application tool for processing ChIP-chip and ChIP-seq data. Bioinformatics 2011, 27(3):428-430.

31. Smoot ME, Ono K, Ruscheinski J, Wang PL, Ideker T: Cytoscape 2.8: new features for data integration and network visualization. Bioinformatics 2011, 27(3):431-432.

32. Obayashi T, Kinoshita K: Rank of correlation coefficient as a comparable measure for biological significance of gene coexpression. DNA Res 2009, 16(5):249-260.

doi:10.1186/1471-2164-15-519

Cite this article as: Chen et al:: Transcriptional regulation and spatial interactions of head-to-head genes. BMC Genomics 2014 15:519.

\section{Submit your next manuscript to BioMed Central and take full advantage of:}

- Convenient online submission

- Thorough peer review

- No space constraints or color figure charges

- Immediate publication on acceptance

- Inclusion in PubMed, CAS, Scopus and Google Scholar

- Research which is freely available for redistribution 